\title{
Duas lições de cartografia fantástica
}

Marilia Rothier Cardoso ${ }^{1}$

\begin{abstract}
The intellectual trajectories of Murilo Mendes and Jorge de Lima intersected at various points since they co-published together the poetry book Time and Eternity, in the thirties. At that same time, they also participated in the Commission on Children's Literature of the Ministry of Education. This secondary activity may serve as a reference point for the examination of the work of both so that they are considered particularly astute "interpreters of Brazil". The poets' participation in that committee reveals, on the one hand, their interest in matters of public interest and, on the other hand, it indicates the theme of childhood as one of the keys to their poetic imagination. It should be emphasized that these two poets never accepted the authoritarian orientation of the nationalist modernization of those years. The children's gaze helped them to create poetic images that are contrary to the stereotype of the nationalist formation. Since their youth work until the more daring moments of their adult poetry, the two artists were able to produce an increasingly powerful effect in order to offer consistent and desirable images of the nation.
\end{abstract}

Keywords: modern Brazilian poetry; children's artistic perspective; critical images of the nation.

Resumo: As trajetórias de Murilo Mendes e Jorge de Lima cruzaram-se em vários pontos desde que, nos anos trinta, publicaram juntos o livro de poemas Tempo e eternidade. Na mesma ocasião, ambos participaram da Comissão de Literatura Infantil do Ministério da Educação. Esta atividade secundária pode servir de ponto de referência para o exame da obra de ambos de modo a considerá-los "intérpretes do Brasil” particularmente argutos. A participação dos poetas nessa comissão revela, de um lado, o interesse público de suas realizações e, de outro lado, indica o tema da infância como uma das chaves de sua imaginação poética. É preciso ressaltar que esses dois poetas nunca aceitaram as orientações autoritárias da modernização nacionalista característica daquele período. O olhar infantil serviu-lhes para que inventassem imagens poéticas contrárias aos estereótipos da formação nacionalista. Desde seus trabalhos de juventude até os momentos mais ousados de sua poesia adulta, os dois artistas conseguiram produzir em sua arte um efeito cada vez mais potente de modo a oferecer imagens consistentes e desejáveis da nação. Palavras-chave: poesia brasileira moderna; infância; perspectiva artística infantil; imagens críticas da nação.

Leitura de poesia é sempre um prazer arriscado. Percebe-se o rigor do pensamento articulando as belas imagens, que fascinam. Difícil apreendê-lo, impossível descartá-lo.

1 Professora Assistente do Depto. de Letras da Pontifícia Universidade Católica do Rio de Janeiro. 
Para evitar o beco sem saída da tentativa de decifração dos versos, pode-se buscar o contraponto entre duas escritas artísticas, pois se espera que uma ilumine a outra. Como apoio, sempre que possível, lança-se mão da pesquisa ao arquivo dos poetas. As poéticas de Jorge de Lima e Murilo Mendes, em sua singularidade complexa, sem dúvida, conversam. Mais irregular, a trajetória do primeiro, à medida que ganhava consistência, foi-se cruzando com a do segundo. Chegaram a publicar um volume juntos, em 1935. Demonstraram muitas afinidades no intercâmbio estético-afetivo. Com sua agudeza crítica, Murilo prefaciou as experiências mais brilhantes e radicais de Jorge. Certamente, o convívio estimulou as ousadias de ambos. Explorando o espaço onde a mística conflui com o fantástico - um tanto à margem do movimento modernista brasileiro, de que foram contemporâneos -, encontraram, na parceria, um modo de combinar vida e obra, tarefas públicas e ação espiritual. Apoiavam um ao outro, quando os críticos lhes davam pouca atenção.

Um documento aparentemente secundário do arquivo de Jorge de Lima (recentemente doado ao Arquivo-Museu de Literatura Brasileira da Fundação Casa de Rui Barbosa) pode servir de referência para o exame da escrita de ambos, enquanto operadores, tão singulares quanto argutos, do que se considera a tarefa de "intérpretes do Brasil". Trata-se do livro de atas da Comissão de Literatura Infantil do Ministério da Educação que, pelos anos 1936 e 1937 (de que datam os registros), avaliava as publicações para crianças com o propósito de selecionar material de bom nível para prêmios e divulgação por parte do governo.

Além de fornecer dados sobre as relações políticas dos dois poetas e mostrar o interesse público de sua atividade intelectual-artística, a participação deles numa tarefa oficial ligada à formação das novas gerações pode conduzir a leitura de sua poesia para a figura da criança como motivo e matéria de criação. Percorrendo a obra de ambos, percebe-se que a contundência crítica da dicção que adotaram resulta, frequentemente, do uso de imagens da linguagem infantil para inaugurar novas perspectivas de enfoque do mundo. Tendo abandonado a proposta nacionalista de seus companheiros de Modernismo, encontraram, no cosmopolitismo fantástico adotado, modos alternativos de denunciar o autoritarismo segregador da ordem político-econômico-social. As figuras - muitas vezes, desconcertantes - com que as crianças caracterizam seu entorno serviu-lhes de baliza no confronto com as convenções do conhecimento e da arte. Em lugar da atenção adulta para o que se considera a história e a geografia reais, no empenho de escavação das origens, descobriram a alegria maior da brincadeira infantil de recortar e colar compondo a arquitetura surreal do mundo imaginário. Aí, desfazem-se os laços familiares, baralham-se as hierarquias, estabelecem-se relações horizontais e a conjunção de temporalidades diversas.

Discordando do trabalho arqueológico da interpretação psicanalítica, Gilles Deleuze observa "o que as crianças dizem" (DELEUZE, 1997, p. 73, 74) e percebe, aí, uma "cartografia dinâmica". As frases das crianças indicam trajetos, deslocamentos de um ambiente a outro e, assim, mudança de "qualidades, substâncias, potências e acontecimentos", na passagem entre os diferentes meios. Segundo o filósofo, os mapas, traçados pela fala infantil, dariam uma descrição mais acurada dos desejos que os conceitos da psicanálise, sempre presos ao triângulo familiar. Com intuição semelhante, os poetas também constroem sua escrita num tempo em "devir" e num espaço demarcado por "intensidades". Mesmo quando tematizam a memória ou se referem às origens, não fixam substâncias, atravessam configurações temporárias, de que registram o desenho em constante transformação. É, sem dúvida, a partir da mesma compreensão da "libido" que Murilo Mendes registra suas (anti)memórias. Aí, o percurso da infância à adolescência corresponde a uma apresentação lírica da aprendizagem poética. Veja-se como se descreve em sua atividade cartográfica: 
Ainda menino eu já colava pedaços da Europa e da Ásia em grandes cadernos. Eram fotografias de quadros e estátuas, cidades, lugares, monumentos, homens e mulheres ilustres, meu primeiro contato com um futuro universo de surpresas. Colava também fotografias de estrelas e planetas, de um ou outro animal e muitas plantas (MENDES, 1994, p. 973).

De seu lado, Jorge de Lima, na imensa colagem de fragmentos poéticos com que persegue o conceito de poesia, enquanto "invenção de Orfeu", encadeia os versos:

Pra unidade deste poema, / ele vai durante a febre, / ele se mescla e se amealha, / e por vezes se devassa. / Não lhe peças nenhum lema / que sua mágoa é engolida, / e a vida vai desconexa, completando o que é teoria, / andaime, saibro, argamassa, / façanha heroica, impudências, / (...) / e pai que me sucedeu / nas guerras que me queimaram, / os sonhos entre as insônias, / infâncias em pleno escuro, / viagens de cima abaixo / unindo as coisas, reunindo, / aliás metamorfoseando-as, (...) (LIMA, 1974, V. 3, p. 43).

Livre da razão e da autoria única, a escrita verbal, visual ou sonora da arte também traça mapas como a fala das crianças. Se assim pensa o filósofo, assim operam os poetas. A arte "é feita de trajetos e devires" (DELEUZE, 1997, p. 78), por isso, Murilo e Jorge servem-se das ações do protagonista infantil ou compõem estrofes acompanhando a mutação contínua dos corpos. Sintomaticamente, o menino constrói mapas e a viagem é o empreendimento desse Orfeu moderno. Avessos à representação realista, os poetas associam palavras pelo ritmo de suas "intensidades", desfazendo seus nexos de significação dicionarizada. Para Deleuze, "a arte se define então como um processo impessoal onde a obra se compõe um pouco como um cairn, esse montículo de pedras trazidas por diferentes viajantes e por pessoas em devir" (p. 78). Numa prática tão revolucionária quanto o conceito do filósofo, os poemas traçam cartografias, com sua variedade surpreendente de imagens apropriadas dos mais diversos discursos. Em sua "unidade" disjunta, a "invenção" do mundo se faz de tudo que a "febre" permite amealhar.

O desenho intrincado como a linguagem de "infâncias em pleno escuro" não permite a tarefa decifratória. Tem-se de atravessar as páginas com os sentidos alerta para a cadência das palavras, o contorno da mancha que imprimem no papel e as imagens que evocam. Outro pensador revolucionário, Walter Benjamin, quando considerou a arte surrealista como "o último instantâneo da inteligência europeia", percebeu que, aí, "a linguagem só parecia autêntica quando o som e a imagem, a imagem e o som, se interpenetravam, com exatidão automática, de forma tão feliz que não sobrava a mínima fresta para inserir a pequena moeda a que chamamos "sentido"' (BENJAMIN, 1985, p. 22). Sem terem participado do movimento francês, Jorge e Murilo sentiram-se atraídos pelas propostas dos manifestos redigidos por Breton e, à sua maneira peculiar, exploraram os efeitos do amálgama - tão potentes quanto distantes das significações convencionais - entre imagem e sonoridade. No longo canto de sextetos em decassílabo, o que ressalta é menos o significado da poesia, que se busca, e muito mais a maneira como o texto toca os sentidos de quem o lê. No caso dos versos citados, o artifício escritural produz conhecimento graças ao impacto de seus sons sibilantes penetrados por reflexos de cor - momento em que a métrica clássica, arrastada em rodopio, arrebata o leitor:

Também os sustos decorridos dantes, / o do encontro com a musa recém-nata / ou com a da infância-musa azul-celeste; / e com essa fugitiva musa sempre, / e desse ardente susto, suas rosas / desabrochando, suave susto nosso (LIMA, 1974, V. 3, p. 205). 
O experimento de Jorge de Lima, dedicado a Murilo Mendes, que o nomeou e prefaciou, visa contaminar as ressonâncias da herança épica com o humor surreal, por sua vez, contagiando este último pela energia sobrevivente da dicção clássica. Muito a propósito, atribuem-se feições infantis à "musa" desse canto que escapa à significação lógica. Um terceiro filósofo, Giorgio Agamben, ajuda a situar a "infância" (AGAMBEN, 2005, p. 5965) como instância da experiência, situada aquém da linguagem. Como os homens têm de aprender a falar, o in-fans é aquele que - antes e depois de dominar os códigos da comunicação - percebe mais do que é possível traduzir em palavras. Esse lugar da experiência muda, do que seria um "murmúrio" diante do mistério (p. 76-78), difícil de apreender pela ciência, frequentemente, na história, foi deslocado para os campos da mística e da poesia. Trata-se do lugar impessoal, pré-subjetivo, que nos acompanha ao logo da vida e indica a fratura entre linguagem e experiência/infância. O recurso aos conceitos filosóficos, na tentativa de apreensão do legado dos dois poetas - usuários da linguagem, enquanto sujeitos impessoais que ultrapassam os limites do código linguístico - propõe-se a desvelar a operação pensante que acompanha a tarefa de construir a arte e que se faz potente à medida que expressa, para além das palavras, a experiência vivida. É certa margem de murmúrio ou balbucio, inscrito na fala articulada, que permite alçar a língua ao plano da poesia, pois inscreve sensações corpóreas nos signos, insuflando vida no pensamento.

Na mesma época em que Jorge compunha Invenção de Orfeu, Murilo Mendes, também empenhado em emprestar rigor clássico aos experimentos da vanguarda rebelde, mostrando seu inconformismo com a ordem sócio-política vigente, compunha os poemas cuja reunião, nomeada Parábola, recebia, como emblema, versos com este mesmo título, que corresponde às figuras de uma trama através da qual se dá corpo a uma linha de pensamento:

A rua, o rolar de remota carruagem; / Intacto o piano, exausta a biblioteca; / A infância em ombrela rosa / E a rosa adormecida no esmalte; / A tradição da febre, a asa fria do pássaro / que não passa, que subsistirá no testemunho: / Eis o que considero por enquanto (MENDES, 1994, p. 548, 549).

Distante da prosa dissertativa, cujo horizonte se restringe às estruturas da linguagem, a poesia extrapola os limites da consciência e expressa um saber onde se misturam iluminações da mente e sensações do corpo. O jogo sonoro das palavras amplifica o efeito das imagens descritas, criando impressão de densidade e materializando o esforço questionador do espírito. Aqui, a insistência incômoda dos rumores do espaço público, que emudecem "o piano" e inutilizam "a biblioteca", remete, necessariamente, à "infância" residual, espaço onde o sujeito avalia as circunstâncias respondendo às percepções visuais e táteis. A lucidez alcançada apresenta-se - e este é o paradoxo do sentido - como delírio da "febre".

Nas etapas iniciais da produção dos dois escritores, surge a presença de um "menino", personagem lírica construída como autoficção, abrindo uma vertente inovadora no projeto poético desenvolvido até então. Em 1925, o moço Jorge de Lima dá uma guinada em sua carreira (erudita) de sonetista precoce e publica o folheto $O$ mundo do menino impossível, onde passa ao tom coloquial e adota o verso livre. O poema, que dá título ao folheto, vai integrar, com alguns outros, o volume Poemas (1927), jogo atrevido de adesão aos experimentos modernistas. Como se lê no referido poema - desde então, tornado antológico -, o "menino" sonha "com esse mundo maravilhoso / que ele tirou do nada" (LIMA, 1974, V. 1, p. 74) e rejeita os hábitos das "crianças mansas" destruindo "os brinquedos perfeitos / que os vovós lhe deram" ["o urso de Nürnberg", "as poupées de Paris aux / cheveux crêpés", "o polichinelo italiano" (p. 73)], para entreter-se com "sabugos de milho, / caixas 
vazias, / tacos de pau / pedrinhas brancas do rio..." (p. 74). A agressividade desses gestos infantis quer ecoar a rebeldia poética do momento, avessa às convenções parnasianas e aos requintes do gosto estrangeiro.

Como "menino impossível", o poeta de vanguarda escolhe as banalidades cotidianas e as tradições populares locais como tema e matéria de sua arte. Mais atrevido ainda, em seus Poemas de estreia (1930), Murilo Mendes já ingressava no campo da nova estética por uma espécie de desvio, apresentando-se na figura do "menino sem passado". Afirma, com ênfase, que "Monstros complicados / não povoaram meus sonhos de criança / porque o saci-pererê não fazia mal a ninguém" e "[a] mãe-d'água só se preocupava / em tomar banhos asseadíssima" (Mendes, 1994, p. 88). Por isso, insiste, "[f]iquei sem tradição sem costumes nem lendas / estou diante do mundo / deitado na rede mole / que todos os países embalam". Se descarta o formalismo da poética oficial, também se mostra cético quanto às palavras de ordem da modernidade nacionalista. Não nega os mitos folclóricos mas duvida de sua potência para reformar as bases da poesia. "Impossível", em sua carência de raízes, a escrita do "Murilo menino" (p. 409, 410) inaugura um espaço cosmopolita de liberdade diante das tradições. É aí que vai desenvolver suas experiências, em crescente radicalidade, tanto com o verso livre quanto com uma prosa lírica de tensa economia.

Bem mais tarde, na elaboração perspectivista de Poliedro (1972), Murilo quebra expectativas, abrindo uma das faces dessa figura múltipla com "O menino experimental", aquele que "devora o livro e soletra o serrote" (Mendes, 1994, p. 1013). Em trajetória mais gradativa rumo à plena inventividade do pensamento artístico, Jorge de Lima atravessa fronteiras para chegar a seu experimento culminante, Invenção de Orfeu (1952). O deus grego, que lhe serve de alter-ego, a um tempo, milenar e recém-nascido, desloca-se por épocas variadas e culturas diferentes. Inscrevendo, nas linhas poéticas, paixões incodificáveis e articulando esses impulsos do corpo com fragmentos de erudição variada, os dois artistas buscam, nas (im)possibilidades do balbucio infantil, a força para por as artes "em pânico". É com esse expediente radical que interpretam o mundo-Brasil que os rodeia.

Em plena maturidade, Jorge e Murilo mostraram-se argutos participantes da dinâmica da cultura. Observando as imagens artísticas (verbais, sonoras, visuais, performáticas) da tradição e aquelas que surgiam em seu tempo, percebiam quais delas, efetivamente, poderiam trazer-lhes energias vitais para que operassem a revolução poética pretendida. Assim, colecionavam as figuras poderosas do passado e do presente (eruditas, populares e massivas) para desarticulá-las e rearticulá-las, abrindo perspectivas inusitadas para o conhecimento. Intuíam que o acervo imagético, formador do imaginário que os tornara poetas, conservava elementos semânticos e fórmulas estilísticas capazes de ultrapassar épocas e padrões de gosto; vindas de espaços culturais distintos, tais imagens - recorrentes ou esquecidas - garantiriam a força de seu verbo inovador. Publicando, em 1938, A poesia em pânico, Murilo Mendes delineia, com os signos da arte, as bases paradoxais de uma teoria dos saberes que derrubam preconceitos epistemológicos e estéticos, justamente por guindarem a violência vanguardista à dignidade clássica. Nessa dicção desconcertante evidencia-se o confronto das paixões coletivas, através de figuras que chocam o chamado bom gosto. Institui-se, então, na linha de frente da arte, uma "segunda natureza":

A figueira estéril voa carregada de frutos / A Vitória da Samotrácia abre os braços na amplidão/ Os navios confabulam soltando a cabeleira ao vento / A múltipla sinfonia avança para mim / Com os quadris em sinos e violoncelos / A mulher de aço me interroga nas altas serras, / Deverei decifrar o seu enigma (MENDES, 1994, p. 290). 
O efeito inesperado de equilíbrio elegante, que resulta dessa associação de referências díspares e expressões esdrúxulas, compondo figuras com partes de seres de espécies incompatíveis, combina fórmulas arcaicas com brincadeiras infantis, estendendo a lição surrealista para além de seu momento inaugural, de modo a resgatar outras dimensões temporais, impensadas pela disciplina historiográfica. Enquanto Murilo continua suas experiências poéticas e, a partir da convivência com Ismael Neri (entre 1921 e 1934), interessa-se pela vanguarda nas artes plásticas, começando a desenvolver um pensamento crítico, Jorge de Lima empenha-se no jogo das formas e cores, empreendendo "tentativas de quadros" (MENDES, in LIMA, 2010, p. 37). Em 1943, seguro das possibilidades questionadoras da "brincadeira" (ANDRADE, in LIMA. 2010, p. 19) de recortar e colar figuras, reúne uma série de 41 fotomontagens e publica A pintura em pânico, com apresentação do parceiro Murilo Mendes.

Para apresentar as fotomontagens, que Mário de Andrade chamou "processo novo de criação lírica" (ANDRADE, in LIMA, 2010, p. 19), o outro poeta-crítico, Murilo, - tendo em vista, certamente, seu trabalho e o do amigo - explica que "[o] pânico é muitas vezes necessário para se chegar à organização" (MENDES. in LIMA, 2010, p. 37), defendendo a conjugação das atividades de destruir e construir. Como amostra das evidentes afinidades entre as escritas verbal e visual, observe-se a fotomontagem que, colocando, em primeiro plano, mãos acorrentadas e um torso e cabeça de estátua clássica, escolhe, como fundo, uma cena portuária, composta de embarcações, guindastes e outras maquinarias (Figura I). Faz contraponto, sem dúvida, com a "Segunda natureza" muriliana, onde "os navios confabulam" diante da "Vitória da Samotrácia" (MENDES, 1994, p. 290). De mármore ou "de aço", ambas as figuras femininas parecem propor um "enigma". Se a função do artista é decifrá-lo, tal tarefa se cumpre pela proposta de outras questões. Por isso mesmo, como título-legenda que acompanha essa colagem lê-se: "A poesia abandona a ciência à sua própria sorte" (LIMA, 2010, p. 60). Na mesma perspectiva de pensamento, que se lança na contracorrente dos nacionalismos programáticos e da ordem estatal autoritária, os artistas propõem sua interpretação cifrada do confronto de forças que constituem o país.

Em pesquisa ao arquivo de Jorge de Lima, observando a variedade insólita de materiais, reservados pelo poeta em busca de temas para os quadros e fragmentos para as colagens, pode-se deduzir que a complexidade crescente de sua poesia, culminando em Invenção de Orfeu, resulta dos exercícios com tesoura e cola. Mais que um regresso às atividades lúdicas da infância, quando se folheiam revistas e colecionam postais, escolhendo imagens atraentes, o impulso artístico reverte o primado do intelecto para a sensibilidade corpórea, acessando aquela dimensão anterior à aquisição da linguagem codificada. A articulação de figuras humanas, animais e vegetais, partes de corpos e órgãos independentes dos mesmos, que compõe a fotomontagem, apresentada pela afirmativa "As coisas começam a engordar, suando dentro de certo ar de luxúria” (LIMA, 2010, p.72, 73), pode ser aproximada, por exemplo, dos sonetos XV e XVI do Canto I de Invenção de Orfeu, onde imagens oníricas e míticas erotizadas sugerem resíduos de devaneios de criança e sobrevivências de ícones arcaicos.

(...) / Essa imagem da vaca, a mais pura e singela / que do fundo do sonho eu às vezes esposo $/ \mathrm{e}$ confunde-se à noite à outra imagem daquela / que ama me amamentou e jaz no último pouso. / (...) / Confundo-os nessa ganga informe que é meu canto: / semblante e leite, a vaca e a mulher que me deu / o leite e a suavidade a mamar de dois seios. //

Desse leite profundo emergido do sonho / coagulou-se essa ilha e essa nuvem e esse rio / (...) / Hoje brota uma flor, amanhã fonte oculta, / e depois de amanhã a memória sepulta / aventuras e fins, relicários e estios; nasce a nova palavra em calendários frios. // Descobrem-se o mercúrio e a febre e a ressonância / e esses velosos pés e o pranto dessa vaca / indo e vindo e nascendo em leite e morte e infância. / (...) (Lima, 1974, p. 37, 38, v. 3) 
Os filósofos que, atualmente, têm-se dedicado ao resgate da epistemologia proposta por Warburg para uma história da arte que abrangesse o conjunto das relações culturais, mostram como as imagens estudadas pelo pesquisador, enquanto "sobrevivências" das fórmulas artísticas antigas, correspondiam a desejos inconscientes, esquecidos ou recalcados no passado (cf. DIDI-HUBERMAN, 2013, p. 134,135; 245; 248, 249). Daí seu aspecto enigmático, quando eram identificadas na grande pintura do renascimento. De modo equivalente, as colagens verbais e visuais dos dois poetas, empenhados em recuperar tendências místicas pelo viés do humor surrealista, apresentam uma evidente correspondência com as investigações registradas pelo Atlas Mnemosyne. Sabe-se que Warburg considerava esse projeto como "uma história de fantasmas para adultos" (AGAMBEN, 2013, p. 123).

Essa denominação serve perfeitamente para caracterizar o legado de Jorge e Murilo. Em desafio à historiografia racionalista, o Atlas Mnemosine compunha-se a partir da pesquisa de indícios culturais fluidos, que escapavam à apreensão como as assombrações dos contos para crianças. Assim também a arte dos poetas brasileiros, à medida que se consolidava, exercia-se num "devir-criança", invocando o "menino experimental e o "menino impossível". Através do humor cruel com que compunham seus roteiros de viagem e suas fantasias cartográficas, iam rompendo as fronteiras das instituições nacionais e inaugurando novos horizontes para se pensar o país.

\section{Referências}

AGAMBEN, Giorgio. Aby Warburg e a ciência sem nome. In: A potência do pensamento. Trad. António Guerreiro. Lisboa: Relógio D’Água, 2013.

AGAMBEN, Giorgio Infância e história. Trad. Henrique Burigo. Belo Horizonte: Ed. UFMG, 2005.

BENJAMIN, Walter. O surrealismo - o último instantâneo da inteligência europeia. In: Magia e técnica, arte e política. Trad. Sergio Paulo Rouanet. São Paulo: Brasiliense, 1985.

DELEUZE, Gilles. O que as crianças dizem. In: Crítica e clínica. Peter Pál Pelbart. São Paulo: Ed. 34, 1997.

DIDI-HUBERMAN, Georges. A imagem sobrevivente; História da arte e tempo dos fantasmas segundo Aby Warburg. Trad. Vera Ribeiro. Rio de Janeiro: Contraponto, 2013.

LIMA, Jorge de. A pintura em pânico. Fotomontagens. Org. Simone Rodrigues. Rio de Janeiro: Caixa Econômica Federal, 2010.

LIMA, Jorge de. Invenção de Orfeu. In: Poesia. Rio de Janeiro: Aguilar, 1974. V. 3. MENDES, Murilo. Poesia completa e prosa. Org. Luciana Stegagno Picchio. Rio de Janeiro: Nova Aguilar, 1994. 